\title{
Global Progressive Disease in Lymph Nodes
}

National Cancer Institute

\section{Source}

National Cancer Institute. Global Progressive Disease in Lymph Nodes. NCI Thesaurus. Code C159961.

50 percent or greater increase in the sum of products of diameter from baseline of lymph nodes; or any new node greater than $1.5 \mathrm{~cm}$ in the long axis or greater than $1 \mathrm{~cm}$ in the short axis if $1-1.5 \mathrm{~cm}$ in the long axis that is proven to be N3 histologically; or loss of response with greater than 50 percent increase from nadir in sum of products of diameter of lymph nodes in those with partial response (whichever occurs first). 